\title{
Spectral invariant behavior of zenith radiance around cloud edges observed by ARM SWS
}

Article

Published Version

Marshak, A., Knyazikhin, Y., Chiu, J. C. and Wiscombe, W. J. (2009) Spectral invariant behavior of zenith radiance around cloud edges observed by ARM SWS. Geophysical Research Letters, 36. L16802. ISSN 0094-8276 doi:

https://doi.org/10.1029/2009GL039366 Available at https://centaur.reading.ac.uk/16763/

It is advisable to refer to the publisher's version if you intend to cite from the work. See Guidance on citing.

Published version at: http://dx.doi.org/10.1029/2009GL039366

To link to this article DOI: http://dx.doi.org/10.1029/2009GL039366

Publisher: American Geophysical Union

All outputs in CentAUR are protected by Intellectual Property Rights law, including copyright law. Copyright and IPR is retained by the creators or other copyright holders. Terms and conditions for use of this material are defined in the End User Agreement.

www.reading.ac.uk/centaur 
Central Archive at the University of Reading

Reading's research outputs online 


\title{
Spectral invariant behavior of zenith radiance around cloud edges observed by ARM SWS
}

\author{
A. Marshak, ${ }^{1}$ Y. Knyazikhin, ${ }^{2}$ J. C. Chiu, ${ }^{3}$ and W. J. Wiscombe ${ }^{1}$ \\ Received 29 May 2009; revised 13 July 2009; accepted 17 July 2009; published 19 August 2009.
}

[1] The ARM Shortwave Spectrometer (SWS) measures zenith radiance at 418 wavelengths between 350 and $2170 \mathrm{~nm}$. Because of its 1-sec sampling resolution, the SWS provides a unique capability to study the transition zone between cloudy and clear sky areas. A spectral invariant behavior is found between ratios of zenith radiance spectra during the transition from cloudy to cloud-free. This behavior suggests that the spectral signature of the transition zone is a linear mixture between the two extremes (definitely cloudy and definitely clear). The weighting function of the linear mixture is a wavelength-independent characteristic of the transition zone. It is shown that the transition zone spectrum is fully determined by this function and zenith radiance spectra of clear and cloudy regions. An important result of these discoveries is that high temporal resolution radiance measurements in the clear-to-cloud transition zone can be well approximated by lower temporal resolution measurements plus linear interpolation. Citation: Marshak, A., Y. Knyazikhin, J. C. Chiu, and W. J. Wiscombe (2009), Spectral invariant behavior of zenith radiance around cloud edges observed by ARM SWS, Geophys. Res. Lett., 36, L16802, doi:10.1029/ 2009 GL039366.

\section{Introduction}

[2] Though clouds seem to have a distinct boundary, remote sensing measurements find it difficult to distinguish between cloudy and cloud free air [Charlson et al., 2007]. This transition zone is neither precisely clear nor precisely cloudy [Koren et al., 2008, 2009]. This problem has major climatic consequences, in particular on aerosol direct and indirect effect studies, which demand a precise separation of clear and cloudy zones.

[3] From satellites, many studies found that the brightness of cloud-free areas systematically increases near clouds [Ignatov et al., 2005; Loeb and Manalo-Smith, 2005; Matheson et al., 2005; Zhang et al., 2005; Koren et al., 2007; Loeb and Schuster, 2008]. The enhanced brightness can result from several factors [Twohy et al., 2009; Varnai and Marshak, 2009], including: small-cloud contamination [e.g., Zhang et al., 2005]; cloud-aerosol microphysics like swelling and increase of number concentration of aerosols in the humid environment near clouds [e.g., Su et al., 2008]; and three-dimensional (3D) radiative interactions between

\footnotetext{
${ }^{1}$ NASA Goddard Space Flight Center, Greenbelt, Maryland, USA.

${ }^{2}$ Department of Geography and Environment, Boston University, Boston, Massachusetts, USA.

${ }^{3}$ Joint Center for Earth Systems Technology, UMBC, Baltimore, Maryland, USA.
}

Copyright 2009 by the American Geophysical Union. 0094-8276/09/2009GL039366\$05.00 clouds and surrounding clear areas [e.g., Wen et al., 2007; Marshak et al., 2008]. Due to enhanced molecular scattering [Wen et al., 2008], the latter leads to a change in spectral color of the scattered light that Marshak et al. [2008] called the "apparent bluing" of the aerosols.

[4] From aircraft, Redemann et al. [2009] used sunphotometer measurements to retrieve aerosol optical depth (AOD). They reported a spectrally neutral increase in AOD in the vicinity of clouds. Su et al. [2008] used High Spectral Resolution Lidar data to infer aerosol properties as a function of the distance from the nearest cloud. In agreement with Redemann et al. [2009], they found an increase in AOD of 10-20\% near clouds compared to far away. Their observed backscatter Angstrom exponents did not show any clear trends near clouds. Recently, Twohy et al. [2009] studied relative humidity as a function of the distance to the boundaries of small cumulus clouds. Areas of enhanced humidity near cloud boundaries are sometimes called "cloud halos" [Perry and Hobbs, 1996; Lu et al., 2003]. Twohy et al. found that the increase in relative humidity close to clouds leads to an increase in scattering cross sections that in turn produces a $35-65 \%$ enhancement in the aerosol direct radiative effect compared to cloud-free areas far away from clouds.

[5] From the ground, Koren et al. [2007] showed that AOD retrieved from AERONET sunphotometers [Holben et al., 1998] decreases with time after the passage of clouds, while Angstrom exponent increases. Chiu et al. [2009] used the Atmospheric Radiation Measurement (ARM) Shortwave Spectrometer (SWS) measurements to study the transition zone between cloud-free and cloudy areas. The SWS is a ground instrument based upon the design of the airborne Solar Spectral Flux Radiometer [Pilewskie et al., 2003]; it measures zenith radiance (field of view $1.4^{\circ}$ ) at 418 wavelengths between 350 and $2170 \mathrm{~nm}$ with 1-s temporal resolution. In the clear-cloud transition zone, Chiu et al. found a remarkable linear relationship between the sum and difference of radiances at 870 and $1640 \mathrm{~nm}$ wavelengths. The intercept of the relationship is determined primarily by aerosol properties, the slope by cloud properties. They also showed that this linearity could be well predicted from simple radiative transfer considerations.

[6] Here we extend the Chiu et al. [2009] analysis using all SWS measurements rather than just two wavelengths. The important questions we address are: what are the fullspectral radiative characteristics of the clear-cloud transition zone; and what is the spectral signature of a weak evaporating cloud? We will also show that SWS observations of the transition zone have wavelength-independent characteristics that were earlier observed in reflectance spectra of vegetated surfaces [Knyazikhin et al., 1998; 


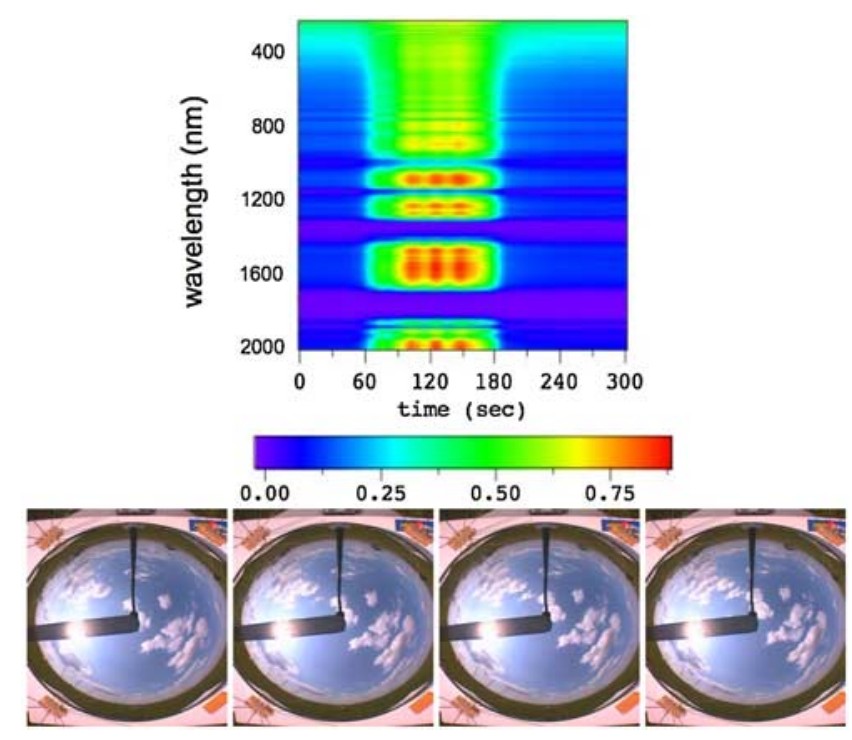

Figure 1. (top) Time-wavelength color contour plot of ARM Short-Wave Spectrometer (SWS) spectra measured from 21:35:24 to 21:40:24 UTC on 18 May 2007 at ARM SGP site in Oklahoma. SZA $=45^{\circ}$ [see Chiu et al., 2009]. SWS-observed zenith radiances have been normalized by $\cos (\mathrm{SZA})$ and by the extraterrestrial solar spectrum (see equation (1)). (bottom) Four total-sky images taken at 21:38:00 (156 s), and 21:38:30 (186 s), 21:39:00 (216 s) and 21:39:30 (246 s) during the time when the small cloud at zenith was moving from inside to outside the field of view of the SWS.

Panferov et al., 2001]. Finally, we discuss how spectral invariant characteristics can be used to study the transition zone.

\section{A Case Study}

[7] We use the ARM SWS measurements of zenith radiance $I_{\mathrm{m}}(t, \lambda)$ at 1 -s temporal resolution and $8 \mathrm{~nm}$ visible and $12 \mathrm{~nm}$ near-infrared spectral resolution. First, we normalize the SWS measurements to an extraterrestrial solar spectrum:

$$
I(t, \lambda)=\frac{\pi I_{m}(t, \lambda)}{\mu_{0} F_{T O A}(\lambda)},
$$

where $\mu_{0}$ is the cosine of solar zenith angle (SZA) and $F_{\mathrm{TOA}}(\lambda)$ is the solar irradiance at the top of the atmosphere. We will focus here on one case fully described by Chiu et al. [2009]. Other cases that we examined showed a similar behavior.

[8] Figure 1 shows a $300 \mathrm{~s}$ segment of normalized spectral zenith radiances measured by SWS on 18 May 2007 at the ARM SGP site. The vertical axis shows wavelength from 350 to $2170 \mathrm{~nm}$. Strong water vapor absorption bands are seen at wavelengths of 930, 1120, 1400 , and $1900 \mathrm{~nm}$. Based on the color palette, we can roughly identify the first $60 \mathrm{~s}$ as clear followed by $120 \mathrm{~s}$ of cloudy and then by $120 \mathrm{~s}$ of clear. The wind speed of $3 \mathrm{~m} / \mathrm{s}$ at cloud-base height of $2.0 \mathrm{~km}$ (derived from the ARM merged sounding product) converts the observation time of $300 \mathrm{~s}$ into $900 \mathrm{~m}$ with a cloud diameter of roughly $360 \mathrm{~m}$. Cloud top height was found at $2.1 \mathrm{~km}$ by lidar and radar, so the cloud was only $100 \mathrm{~m}$ thick. Four total sky images taken $30 \mathrm{~s}$ apart starting from $156 \mathrm{~s}$ indicate that the cloud moves toward the northeast.

\section{Linear Mixture Hypothesis}

[9] Let $t_{0}$ be the time corresponding to the cloud edge. We choose $t_{0}=150 \mathrm{~s}$ for our example (see Figure 1). Let $t_{\mathrm{T}}$ denote the time of definitely clear observations:

$$
t_{\mathrm{T}}=t_{0}+T \text {. }
$$

We will call $T$ the length of the transition zone between cloudy and cloud-free regions, which we take as $T=100 \mathrm{~s}$ in our analysis. With a wind speed of $3 \mathrm{~m} / \mathrm{s}, T$ corresponds to a $300 \mathrm{~m}$ spatial segment. Figure 2 illustrates the normalized zenith radiance spectrum plotted at $10 \mathrm{~s}$ time intervals from $t_{0}=150 \mathrm{~s}$ to $t_{\mathrm{T}}=250 \mathrm{~s}$.

[10] Now we are ready to state our hypothesis, namely: spectra in the transition zone, such as those in Figure 2, are a linear combination of cloudy (time $t_{0}$ ) and clear sky (time $t_{\mathrm{T}}$ ) spectra with a wavelength-independent weight $a(t)$,

$I(t, \lambda)=a(t) I\left(t_{0}, \lambda\right)+[1-a(t)] I\left(t_{T}, \lambda\right), \quad t \in\left(t_{0}, t_{T}\right)$, $a(t) \in(0,1)$,

where $a(t)$ is a monotonically decreasing function with $a\left(t_{0}\right)=1$ and $a\left(t_{\mathrm{T}}\right)=0$.

[11] Dividing equation (3) by clear sky spectral radiance, $I\left(t_{\mathrm{T}}, \lambda\right)$, results in the following relationship between the transition-zone and cloudy sky observations:

$$
\begin{aligned}
\frac{I(t, \lambda)}{I\left(t_{T}, \lambda\right)} & =a(t) \frac{I\left(t_{0}, \lambda\right)}{I\left(t_{T}, \lambda\right)}+b(t), \quad t \in\left(t_{0}, t_{T}\right), \quad a(t) \in(0,1), \\
b(t) & =1-a(t) .
\end{aligned}
$$

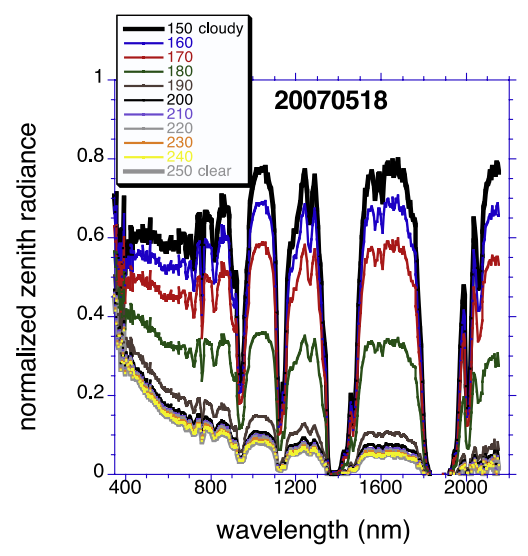

Figure 2. Normalized SWS zenith radiance spectrum measured on 18 May 2007 from $t_{0}=150 \mathrm{~s}$ (cloudy) to $t_{\mathrm{T}}=250 \mathrm{~s}$ (clear) with $10 \mathrm{~s}$ time interval. Same case as Figure 1. 

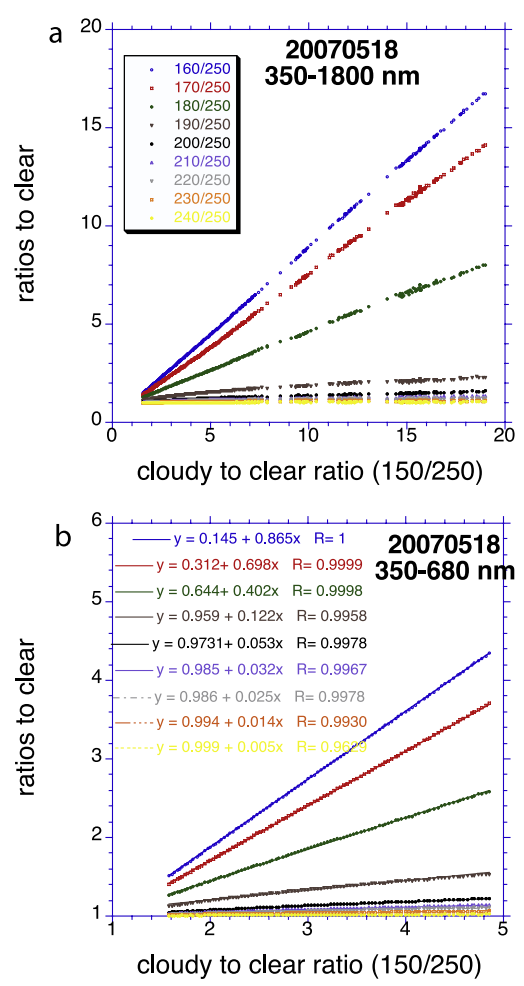

Figure 3. Ratio $y_{t}(\lambda)$ vs. ratio $x(\lambda)$ for 9 values of time from $t=160 \mathrm{~s}$ to $t=240 \mathrm{~s}$ (see equation (5)) with linear fit and the coefficients of linear regression. (a) Wavelengths from 350 to $1800 \mathrm{~nm}$. (b) Wavelengths from $350 \mathrm{~nm}$ to $680 \mathrm{~nm}$. 18 May 2007 case of Figure 1. To avoid division by small numbers (see Figure 2) we excluded these strong water vapor absorbing spectral intervals: 931-970 nm, $1087-1164 \mathrm{~nm}, 1301-1495 \mathrm{~nm}$, and 1800-1960 nm. We have also masked spectral measurements at wavelengths longer that $2000 \mathrm{~nm}$ because the clear sky values of zenith radiance at these wavelengths are too low and too uncertain to be used as a denominator in equation (4).

For simplicity, let us rewrite equation (4) as

$$
y_{t}(\lambda)=a(t) x(\lambda)+b(t)
$$

where

$$
y_{t}(\lambda)=I(t, \lambda) / I\left(t_{T}, \lambda\right), \quad x(\lambda)=I\left(t_{0}, \lambda\right) / I\left(t_{T}, \lambda\right) .
$$

We will check $(i)$ how good the linear relationship equation (5) is; and (ii) how different the sum $a(t)+b(t)$ is from unity.

[12] Figure 3 plots $y_{t}(\lambda)$ vs. $x(\lambda)$ for 9 values of time $t$ between $160 \mathrm{~s}$ and $250 \mathrm{~s}$. The upper panel demonstrates $y_{t}$ vs. $x_{t}$ relationships using data from 350 to $1800 \mathrm{~nm}$ while the lower panel shows just the visible spectral interval. Very high values of the linear regression coefficient suggest a nearly perfect linear variation with slope $a(t)$ and intercept $b(t)$ adding up to unity with $2-5 \%$ uncertainties (at $190 \mathrm{~s}$ the sum deviated most from unity, 1.08). Clearly, the linear relationship does not depend on wavelength, and thus $a(t)$ does not depend on wavelength.

[13] It is not surprising that $a(t)+b(t)=1$. Indeed, as $\lambda$ goes toward UV wavelengths where Rayleigh scattering increasingly dominates cloud scattering, the difference between clear and cloudy zenith radiance becomes smaller (see Figures 1 and 2 ) and $I(t, \lambda) \approx I\left(t_{0}, \lambda\right) \approx I\left(t_{\mathrm{T}}, \lambda\right)$. As a result, equation (4) leads to $a(t)+b(t) \approx 1$.

\section{Spectrally-Invariant Function}

[14] We first estimate a rate at which the spectral zenith radiance decreases while going from cloudy to clear regions. Differentiating both sides of equation (3), we find that

$$
\frac{\partial I(t, \lambda)}{\partial t}=a^{\prime}(t)\left[I\left(t_{0}, \lambda\right)-I\left(t_{T}, \lambda\right)\right]
$$

Thus, the derivative of spectral-invariant function $a(t)$ and zenith radiance spectra of cloudy and cloud-free sky areas fully determine the behavior of $I(t, \lambda)$ and its variability (as a function of $t$ ) in the transition zone.

[15] Figure 4 illustrates the behavior of functions $a(t)$ in the transition zone. In addition, we have also plotted $I(t, \lambda)$ for three wavelengths: 440, 870, and $1640 \mathrm{~nm}$. Zenith radiance at each wavelength shows the (wavelengthdependent) signature of a small evaporating cloud. For example, because of smaller aerosol optical depth and lack of Rayleigh scattering, zenith radiance at $1640 \mathrm{~nm}$ has a stronger contrast between cloudy and cloud-free areas than that at $440 \mathrm{~nm}$. We hypothesize here that the wavelength independent function $a(t)$ depends only on the intrinsic cloud structure near its boundaries and is only weakly sensitive to surface spectral albedo. If a cloud has a sharp boundary, $a(t)$ will be more like the Heaviside step-function. However, it is much smoother for a slowly fading cloud. We suggest that $a(t)$ can be used to identify clouds of different types and ages (I. Koren, private communication, 2009) and we expect it to be especially helpful in distinguishing between water and ice clouds as well as between polluted and clean environments. These results will be reported elsewhere.

[16] Spectral invariant behavior found in the transition zone between cloudy and cloud-free areas is surprising. In vegetation canopy, linear relationships between some algebraic combinations of measured reflectance, transmittance and absorptance of shortwave spectra have recently been

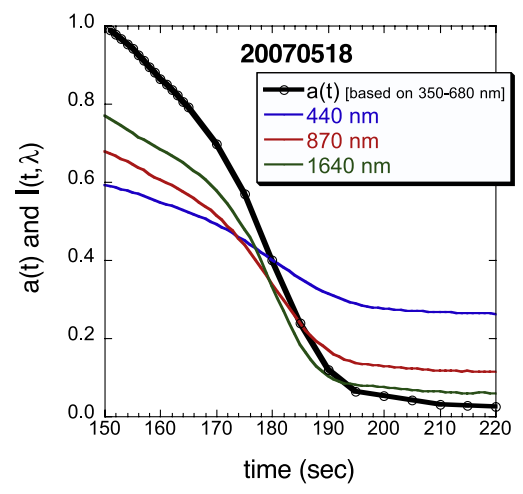

Figure 4. Spectral-invariant functions $a(t)$ for many wavelengths co-plotted with normalized zenith radiance $I(t, \lambda) .18$ May 2007 case of Figure 1. 
observed and physics behind such phenomena have been documented [Panferov et al., 2001, Huang et al., 2007, Knyazikhin et al., 1998]. The slope and intercept of the relationships are indicative of canopy micro- and macroproperties [Smolander and Stenberg, 2005; Lewis and Disney, 2007]. Search for similar phenomena in clouds and understanding of their physics are essential to better understanding of cloud observations since it allows separation of the structural and radiometric components of measured signal.

\section{Summary and Discussion}

[17] Analyzing high spectral and temporal resolution Shortwave Spectrometer (SWS) measurements of zenith radiance led to the surprising discovery of a wavelengthindependent function $a(t)$ of time $t$ that characterizes the transition zone between cloudy and cloud-free areas. The transition zone spectrum is fully determined by $a(t)$ and zenith radiances spectra of clear and cloudy sky areas. This finding is essential to both remote sensing and modeling communities. For example, high temporal resolution zenith radiance measurements in the transition zone can be approximated by low temporal resolution spectral data using a simple linear interpolation between measurements at cloudy and cloud-free areas.

[18] If spectral-invariance of the transition zone is established, the behavior of $a(t)$ can be studied using only two wavelengths. For example, the high temporal resolution 2-channel (673 and $870 \mathrm{~nm}$ ) ARM Narrow Field of View (2NFOV) radiometer [Marshak et al., 2004; Chiu et al., 2006] is a perfect tool to derive spectrally independent characteristics of cloud edges and this application will be reported elsewhere.

[19] Koren et al. [2009] and Jiang et al. [2009] have recently studied the transition zone using high-resolution Large Eddy Simulation output. They found much sharper cloud edges in polluted environments compared to their cleaner counterparts. They suggested that for small cumulus clouds aerosols enhance evaporation of the regions with low cloud liquid water, i.e., there is stronger evaporation at cloud edges in the case of polluted clouds. This leads to a more rapid decrease in liquid water path with distance from cloud. Thus, the spectral invariant function $a(t)$ may serve as a good characteristic of pollution in a field with small cumulus clouds. Moreover, if the transition zone between ice clouds and cloud-free area is longer and smoother than between water clouds and cloud-free area, the spectral invariant function $a(t)$ may help determine the thermodynamic phase.

[20] As the very next step, we will check the spectral invariant behavior of the normalized to clear sky zenith radiance in the transition zone using a simple $1 \mathrm{D}$ radiative transfer model. We will check numerically how sensitive the spectral invariant function $a(t)$ to SZA and to variations in spectral surface albedo, as well as to degrees of aerosol loading. Then we apply a 3D radiative transfer model [e.g., Pincus and Evans, 2009] at different wavelengths to largeeddy simulations of cumulus clouds [Jiang et al., 2009] for clean and polluted atmospheres.

[21] Acknowledgments. This research is supported by the Office of Science (BER, U.S. Department of Energy, Interagency Agreements DEAI02-08ER64562, DE-FG02-08ER64563, and DE-FG02-08ER54564) as part of the ARM program. We also thank H. Barker, G. Feingold, P. Kiedron, I. Koren, A. Kostinski, Q. Min, P. Pilewskie, J. Redemann, and T. Varnai for fruitful discussions. We are very grateful to Connor Flynn of the ARM Program for help in understanding and correcting the SWS data.

\section{References}

Charlson, R., A. Ackerman, F. Bender, T. Anderson, and Z. Liu (2007), On the climate forcing consequences of the albedo continuum between cloudy and clear air, Tellus, Ser. B, 59, 715-727, doi:10.1111/j.16000889.2007.00297.x

Chiu, J. C., A. Marshak, Y. Knyazikhin, W. J. Wiscombe, H. W. Barker, J. C. Barnard, and Y. Luo (2006), Remote sensing of cloud properties using ground-based measurements of zenith radiance, J. Geophys. Res., 111, D16201, doi:10.1029/2005JD006843.

Chiu, J. C., A. Marshak, Y. Knyazikhin, P. Pilewskie, and W. Wiscombe (2009), Physical interpretation of the spectral radiative signatures in the transition zone between cloud-free and cloudy regions, Atmos. Chem. Phys., 9, 1419-1430.

Holben, B. N., et al. (1998), AERONET-A federated instrument network and data archive for aerosol characterization, Remote Sens. Environ., 66, 1-16, doi:10.1016/S0034-4257(98)00031-5.

Huang, D., et al. (2007), Canopy spectral invariants for remote sensing and model applications, Remote Sens. Environ., 106, 106-122, doi:10.1016/ j.rse.2006.08.001.

Ignatov, A., P. Minnis, N. Loeb, B. Wielicki, W. Miller, S. Sun-Mack, D. Tanre, L. Remer, I. Laslo, and E. Geier (2005), Two MODIS aerosol products over ocean on the Terra and Aqua CERES SSF, J. Atmos. Sci., 62, 1008-1031, doi:10.1175/JAS3383.1.

Jiang, H., G. Feingold, and I. Koren (2009), Effect of aerosol on trade cumulus cloud morphology, J. Geophys. Res., 114, D11209, doi:10.1029/2009JD011750.

Knyazikhin, Y., J. V. Martonchik, R. B. Myneni, D. J. Diner, and S. W. Running (1998), Synergistic algorithm for estimating vegetation canopy leaf area index and fraction of absorbed photosynthetically active radiation from MODIS and MISR data, J. Geophys. Res., 103, 32,257-32,274, doi:10.1029/98JD02462.

Koren, I., L. A. Remer, Y. J. Kaufman, Y. Rudich, and J. V. Martins (2007), On the twilight zone between clouds and aerosols, Geophys. Res. Lett., 34, L08805, doi:10.1029/2007GL029253.

Koren, I., L. Oreopoulos, G. Feingold, L. A. Remer, and O. Altaratz (2008), How small is a small cloud?, Atmos. Chem. Phys., 8, 3855-3864.

Koren, I., G. Feingold, H. Jiang, and O. Altaratz (2009), Aerosol effects on the inter-cloud region of a small cumulus cloud field, Geophys. Res. Lett., 36, L14805, doi:10.1029/2009GL037424.

Lewis, P., and M. Disney (2007), Spectral invariants and scattering across multiple scales from within-leaf to canopy, Remote Sens. Environ., 109, 196-206, doi:10.1016/j.rse.2006.12.015.

Loeb, N. G., and N. Manalo-Smith (2005), Top-of-atmosphere direct radiative effect of aerosols over global oceans from merged CERES and MODIS observations, J. Clim., 18, 3506-3526, doi:10.1175/ JCLI3504.1

Loeb, N. G., and G. L. Schuster (2008), An observational study of the relationship between cloud, aerosol and meteorology in broken low-level cloud conditions, J. Geophys. Res., 113, D14214, doi:10.1029/ 2007JD009763.

Lu, M.-L., J. Wang, A. Freedman, H. H. Jonsson, R. C. Flagan, R. A. McClatchey, and J. H. Seinfeld (2003), Analysis of humidity halos around trade wind cumulus clouds, J. Atmos. Sci., 60, 1041-1059, doi:10.1175/1520-0469(2003)60<1041:AOHHAT>2.0.CO;2.

Marshak, A., Y. Knyazikhin, K. D. Evans, and W. J. Wiscombe (2004), The "RED versus NIR" plane to retrieve broken-cloud optical depth from ground-based measurements, J. Atmos. Sci., 61, 1911-1925, doi:10.1175/1520-0469(2004)061<1911:TRVNPT>2.0.CO;2.

Marshak, A., G. Wen, J. A. Coakley Jr., L. A. Remer, N. G. Loeb, and R. F. Cahalan (2008), A simple model for the cloud adjacency effect and the apparent bluing of aerosols near clouds, J. Geophys. Res., 113, D14S17, doi:10.1029/2007JD009196.

Matheson, M. A., J. A. Coakley Jr., and W. R. Tahnk (2005), Aerosol and cloud property relationships for summertime stratiform clouds in the northeastern Atlantic from AVHRR observations, J. Geophys. Res., 110, D24204, doi:10.1029/2005JD006165.

Panferov, O., Y. Knyazikhin, R. B. Myneni, J. Szarzynski, S. Engwald, K. G. Schnitzler, and G. Gravenhorst (2001), The role of canopy structure in the spectral variation of transmission and absorption of solar radiation in vegetation canopies, IEEE Trans. Geosci. Remote Sens., 39, 241-253, doi:10.1109/36.905232

Perry, K. D., and P. V. Hobbs (1996), Influences of isolated cumulus clouds on the humidity of their surroundings, J. Atmos. Sci., 53, 159-174, doi:10.1175/1520-0469(1996)053<0159:IOICCO>2.0.CO;2. 
Pilewskie, P., J. Pommier, R. Bergstrom, W. Gore, S. Howard, M. Rabbette, B. Schmid, P. V. Hobbs, and S. C. Tsay (2003), Solar spectral radiative forcing during the Southern African Regional Science Initiative, J. Geophys. Res., 108(D13), 8486, doi:10.1029/2002JD002411.

Pincus, R., and K. F. Evans (2009), Computational cost and accuracy in calculating three-dimensional radiative transfer: Results for new implementations of Monte Carlo and SHDOM, J. Atmos. Sci., in press.

Redemann, J., Q. Zhang, P. B. Russell, J. M. Livingston, and L. A. Remer (2009), Case studies of aerosol remote sensing in the vicinity of clouds, J. Geophys. Res., 114, D06209, doi:10.1029/2008JD010774.

Smolander, S., and P. Stenberg (2005), Simple parameterizations of the radiation budget of uniform broadleaved and coniferous canopies, Remote Sens. Environ., 94, 355-363, doi:10.1016/j.rse.2004.10.010.

$\mathrm{Su}$, W., G. L. Schuster, N. G. Loeb, R. R. Rogers, R. A. Ferrare, C. A. Hostetler, J. W. Hair, and M. D. Obland (2008), Aerosol and cloud interaction observed from high spectral resolution lidar data, J. Geophys. Res., 113, D24202, doi:10.1029/2008JD010588.

Twohy, C. H., J. A. Coakley Jr., and W. R. Tahnk (2009), Effect of changes in relative humidity on aerosol scattering near clouds, J. Geophys. Res., 114, D05205, doi:10.1029/2008JD010991.

Varnai, T., and A. Marshak (2009), MODIS observations of enhanced clear sky reflectance near clouds, Geophys. Res. Lett., 36, L06807, doi:10.1029/2008GL037089.
Wen, G., A. Marshak, R. F. Cahalan, L. A. Remer, and R. G. Kleidman (2007), 3-D aerosol-cloud radiative interaction observed in collocated MODIS and ASTER images of cumulus cloud fields, J. Geophys. Res., 112, D13204, doi:10.1029/2006JD008267.

Wen, G., A. Marshak, and R. F. Cahalan (2008), Importance of molecular Rayleigh scattering in the enhancement of clear sky reflectance in the vicinity of boundary layer cumulus clouds, J. Geophys. Res., 113, D24207, doi:10.1029/2008JD010592.

Zhang, J., J. S. Reid, and B. N. Holben (2005), An analysis of potential cloud artifacts in MODIS over ocean aerosol optical thickness product, Geophys. Res. Lett., 32, L15803, doi:10.1029/2005GL023254.

J. C. Chiu, Joint Center for Earth Systems Technology, UMBC, 5523 Research Park Drive, Suite 320, Baltimore, MD 21228, USA.

Y. Knyazikhin, Department of Geography and Environment, Boston University, 675 Commonwealth Avenue, Room 334J, Boston, MA 02215, USA.

A. Marshak and W. J. Wiscombe, NASA Goddard Space Flight Center, Mail Code 613.2, Greenbelt, MD 20771, USA. (alexander.marshak-1@ nasa.gov) 